\title{
AMF O uso das redes sociais nas Instituições de Ensino Superior
}

\author{
Ana Paula dos Santos Cardias ${ }^{1}$ \\ Ezequiel Redin ${ }^{2}$
}

\begin{abstract}
Resumo: Hodiernamente, devido à tecnologia da informação e comunicação proporcionar a aproximação virtual e manutenção de relacionamentos entre pessoas e organizações, empresas de todos os ramos, inclusive instituições de ensino, procuram estar presentes no ambiente virtual, por meio das redes sociais. Nesse sentido, o estudo verificou o comportamento de duas instituições de ensino superior gaúchas nas redes sociais. Para tanto, foram avaliados os seguintes parâmetros: frequência de postagens, conteúdo divulgado, interação com o público e propagação das publicações, de modo a identificar a influência que isso representa para a comunicação entre organização e público-alvo. Tomando por base a análise dos perfis oficiais das instituições nas redes sociais (Facebook e Instagram) e a utilização de instrumentos de pesquisa, conclui-se que o número de seguidores e o nível de interação representam variáveis independentes. A interação, por sua vez, depende de fatores como a proposta da rede social, tipos específicos de conteúdo, horários de postagens, mas, principalmente, da capacidade das instituições em estimular a cultura participativa dos usuários. A imagem de uma instituição em si está diretamente relacionada com a capacidade de comunicação com o seu público-alvo.
\end{abstract}

Palavras-chave: Marketing digital; redes sociais; relacionamento; Instituições de Ensino Superior.

Abstrac: Today, because information and communication technology provides
the virtual approach and maintenance of relationships between people and
organizations, companies from all branches, including educational institutions,
seek to be present in the virtual environment through social networks. In this
sense, the study verified the behavior of two higher education institutions in Rio
Grande do Sul in social networks. To this end, the following evaluation
parameters were analyzed: frequency of posts, published content, interaction
with the public and propagation of publications, in order to identify the
influence that this represents for the communication between the organization
and the target audience. Based on the analysis of the official profiles of social
network institutions (Facebook and Instagram) and the use of research tools, it
is concluded that the number of followers and the level of interaction represent
independent variables. Interaction, in turn, depends on factors such as the
proposal of the social network, specific types of content, posting times, but
especially on the ability of institutions to stimulate the participatory culture of

${ }^{1}$ Bacharel em Administração pela Faculdade Metodista de Santa Maria.

2 Tecnólogo em Agropecuária: Sistemas de Produção (UERGS) CREA RS 160488; Bacharel em Administração (ULBRA); Licenciatura plena para a Educação Profissional (UFSM); Especialista em Gestão Pública Municipal (UFSM); Especialista em Tecnologias de Informação e Comunicação aplicadas à Educação (UFSM); Especialista em Ensino de Sociologia no Ensino Médio (UFSM); Especialista em Ensino de Filosofia no Ensino Médio (UFSM); Mestre e Doutor em Extensão Rural (PPGExR/UFSM É professor do Programa de Pós-Graduação em Estudos Rurais (PPGER) e do Instituto de Ciências Agrárias (ICA) da Universidade Federal dos Vales do Jequitinhonha e Mucuri (UFVJM) - Campus Unaí, MG. 
users. The image of an institution itself is directly related to its ability to communicate with its target audience.

Keywords: Digital Marketing; social networks; relationship; Higher education institutions.

Resumen: Hoy, debido la tecnología de la información y la comunicación proporcionar el enfoque virtual y el mantenimiento de las relaciones entre las personas y las organizaciones, las empresas de todas las ramas, incluidas las instituciones educativas, buscan estar presentes en el entorno virtual a través de las redes sociales. En este sentido, el estudio verificó el comportamiento de dos instituciones de educación superior en Rio Grande do Sul en las redes sociales. Con este fin, se evaluaron los siguientes parámetros: frecuencia de publicaciones, contenido publicado, interacción con el público y propagación de publicaciones, con el fin de identificar la influencia que esto representa para la comunicación entre la organización y el público objetivo. Basado en el análisis de los perfiles oficiales de las instituciones de redes sociales (Facebook e Instagram) y el uso de herramientas de investigación, se concluye que el número de seguidores y el nivel de interacción representan variables independientes. La interacción, a su vez, depende de factores como la propuesta de la red social, tipos específicos de contenido, tiempos de publicación, pero especialmente de la capacidad de las instituciones para estimular la cultura participativa de los usuarios. La imagen de una institución en sí está directamente relacionada con su capacidad de comunicarse con su público objetivo.

Palabras clave: Marketing digital; redes sociales; relación Instituciones de educación superior.

\section{Introdução}

No decorrer dos dois últimos séculos, as evoluções tecnológicas provocaram mudanças no comportamento dos consumidores, nos mercados e na utilização das estratégias de marketing. A era industrial acelerou o desenvolvimento da tecnologia de produção, e, posteriormente, a era da informação, com as tecnologias da informação e comunicação e o surgimento da internet, impulsionaram a participação das pessoas em redes de relacionamentos, com o foco na interatividade e conectividade entre indivíduos (KOTLER, 2012). À medida que o processo de ascensão das tecnologias digitais interativas tornou-se presente entre os indivíduos, afetou, também, o modo como estava sendo trabalhado o marketing, que passou a ser influenciado e impactado pelas mídias digitais. Nesse sentido, as organizações precisaram se adaptar a esse novo momento com vistas a manter o foco inicial que é a satisfação das necessidades e desejos dos consumidores (GABRIEL, 2010). 
Ciente deste cenário de troca de informações e relacionamentos entre redes, vários tipos de organizações, incluindo Instituições de Ensino Superior (IES), buscaram fazer-se presentes no meio digital (MONDINI et al., 2012). Conforme Rocha Júnior et al. (2014), estudos realizados por autores como Lenhart, Madden e Hitlin (2005), Debell e Chapman (2006), e Lenhart et al. (2008) apontam que as redes sociais são utilizadas por estudantes com a finalidade de interagir e construir relacionamentos com outros usuários. Razão pela qual fez com que essas instituições optassem pelo uso de redes sociais para interagir com alunos atuais, potenciais e ex-alunos (ROCHA JÚNIOR et al., 2014).

Nesse contexto, o estudo delimitou-se em pesquisar duas Instituições de Ensino Superior (IES) do Rio Grande do Sul, ambas caracterizadas como universidades, e o seu comportamento nas redes sociais. Portanto, o problema de pesquisa se deteve a responder à seguinte questão: Qual o comportamento no uso das redes sociais por IES pública e privada do Rio Grande do Sul? O objetivo consistiu, portanto, em analisar o comportamento percebido nas redes sociais de duas Instituições de Ensino Superior no Rio Grande do Sul, dando ênfase ao campus sede de cada uma delas, identificando a sua influência para a comunicação entre IES e seu público-alvo, inserido ao contexto do marketing digital.

A relevância do tema tratado neste estudo está presente no uso do marketing digital, que se torna atrativo devido à visibilidade $\mathrm{e}$ aos relacionamentos interativos proporcionados pelo uso das redes sociais (LEMES; GHISLENI, 2013) e ao fato de que, quando usado por IES, melhora a interação com os alunos que estão sempre conectados ao mundo digital, proporcionando assim, uma rede de trocas de informações por um custo baixo (ROCHA JÙNIOR et al., 2014). Sendo assim, analisar essa temática possibilita a percepção e entendimento acerca da influência das redes sociais dentro do marketing digital, quando utilizadas por IES, levando em consideração quesitos como divulgação da imagem institucional e da comunicação e, por consequência, o nível de propagação gerado através de suas publicações e manifestações digitais.

\section{Marketing Digital e Educacional nas Instituições Superiores}

O uso das redes sociais por qualquer tipo de organização, inclusive Instituições de Ensino Superior, funciona como uma ferramenta que auxilia na obtenção e troca de informações, devido a sua capacidade de facilitar e proporcionar a interação entre 
indivíduos. Portanto, esta seção trata sobre conceitos e justificativas a respeito da revisão de literatura já realizada por outros autores, sobre a temática relacionada ao uso de redes sociais dentro do marketing digital. Para tanto, são levados em consideração conceitos a respeito do marketing digital, as redes sociais e sua função, além do marketing educacional.

\subsection{Marketing digital}

Por mais que as empresas possuam conhecimento de como se relacionar com seus clientes, surgem novas tecnologias digitais com potencial de fortalecer essa interação. A internet, por exemplo, é um canal que proporciona para as empresas o estreitamento de laços dos consumidores com suas marcas devido à possibilidade de diálogo em tempo real (BRANDÃO, 2001).

As tecnologias possuem a responsabilidade de configurar uma visão de mundo dos membros da sociedade e suprir suas necessidades por trocas de informações. Elas impactam diretamente nas empresas, podendo alterar suas estruturas e influenciar no relacionamento com os clientes. Se antes elas precisavam de um local físico para atender aos clientes, já não é um fator obrigatório (BRANDÃO, 2001). Como resposta aos avanços tecnológicos e ao crescimento da internet, surgiu o marketing digital, uma ferramenta complementar ao marketing tradicional, que se responsabiliza por otimizar os esforços de um planejamento estratégico voltado para o posicionamento empresarial. Por meio dele, busca-se melhorar a interação entre organizações e consumidores, bem como, realizar a manutenção da imagem corporativa da empresa, mas agora no meio digital (CRUZ; SILVA, 2014; LEMES; GHISLENI, 2013).

Conforme Rocha Júnior et al. (2014), tanto o marketing digital quanto o tradicional possuem os mesmos objetivos, ou seja, possuem um público-alvo, buscam criar relacionamentos duradouros com seus clientes e querem promover e ampliar seus negócios. Para Kotler (1994), o marketing, em sua totalidade, busca por troca de valores com o seu público-alvo, ou seja, os profissionais de marketing esperam por algum retorno após seus projetos atingirem o mercado pretendido (KOTLER, 1994; ROCHA JÚNIOR et al., 2014).

Para implementar o marketing digital, a empresa precisa difundir informações sobre si para os clientes por meio de publicações nos meios sociais, convidando-os a participar 
do desenvolvimento da sua imagem e de suas comunicações (KOTLER, 2012). Conforme Lemes e Ghisleni (2013), a divulgação por esse meio, diferente do marketing tradicional, permite realizar um número ilimitado de divulgações, possui propagação rápida e por um custo baixo. De acordo com Souza (2012), a eficácia do marketing digital acontece pelo fato que sua adesão é gratuita, ou seja, as empresas não despendem de capital para utilizar essa ferramenta e, ainda assim, em benefício, recebem algum lucro como retorno.

Embora os conceitos se refiram à internet de uma forma geral, este estudo leva em consideração apenas sites de redes sociais, especificamente, o Facebook e o Instagram, que estão em alta no universo digital atual. Segundo Kotler (2012), as mídias sociais são o futuro das comunicações de marketing, pois apresentam baixo custo, são uma nova fonte de colaboração entre usuários e por afetarem o trabalho dos profissionais encarregados dessa tarefa. De uma forma geral, as tecnologias digitais funcionam como um complemento do mix de ações empresariais (BRANDÃO, 2001).

De acordo com Lemes e Ghisleni (2013), a utilização do marketing digital tornase atrativa devido à visibilidade das mídias sociais e dos relacionamentos interativos das redes sociais. Contudo, para ser eficiente na abordagem e utilização do marketing digital, é necessário que a empresa possua profissionais capacitados e com conhecimentos especializados a respeito da publicidade online como também tenha um planejamento que favoreça a comunicação da marca de forma adequada ao seu público.

Diante desse cenário de importância do meio digital, influenciado pelo relacionamento e pela visibilidade entre empresas e clientes, e pela escolha da utilização do marketing digital pelas empresas, a próxima seção apresenta conceitos e o contexto da utilização das redes sociais na atualidade em prol do marketing digital.

\subsection{As redes socias e sua função}

A ascensão das redes sociais aconteceu devido ao seu conceito de interação e à ideia de um ambiente informal (PATRÍCIO; GONÇALVES, 2010). Com o tempo, as empresas que mantinham contato apenas por meios analógicos migraram para os meios digitais a fim de acompanhar a evolução e os clientes (OLIVEIRA, 2014). Muitas delas deixaram de possuir seus sites institucionais para também atingir um público mais amplo (SOUZA; AZEVEDO, 2010). Por conta disso, é fácil encontrar empresas que possuam uma fanpage (página de fãs) no Facebook e também uma conta no Instagram (OLIVEIRA, 
2014).

O site institucional de uma empresa reflete sua identidade para o coletivo, contendo informações de sua autoria. Já as redes sociais também podem conter assuntos institucionais sem ser considerada um site institucional. Para Souza e Azevedo (2010), o que difere de um para o outro é a temática e o objetivo. As redes sociais, por exemplo, conduzem os usuários a um ambiente de relacionamento e interação entre pessoas (NASSAR; VIEIRA, 2017), tais características tornam o alcance dessa ferramenta ainda maior. Vale ressaltar que há diferença entre redes sociais e mídias sociais, embora sejam consideradas erroneamente como sinônimas. A mídia social é o meio utilizado para que uma rede social exerça a comunicação (CIRIBELI; PAIVA, 2011).

Logo, as redes são definidas como sinônimo de fenômenos coletivos que influenciam no relacionamento entre grupos, pessoas e organizações, possibilitando relações de trabalho, amizade, estudo, entre outras, em que, a cada conexão ou interação, são geradas novas informações. Devido a essas redes, as relações sociais ocorrem independentes do espaço ou do tempo, possibilitando a interação de grupos por meio de relacionamentos e interesses comuns (TOMAÉL, 2005). Uma das redes que proporcionam esse tipo de interação é o Facebook. O Facebook foi criado em 2004 pelo norte-americano Mark Zuckerberg, com uso exclusivo para alunos da Universidade de Harvard, mas, em 2006, o acesso expandiu-se para uso mundial. Sua utilização acontece por meio da criação de perfis e grupos, nos quais os usuários trocam mensagens públicas e/ou privadas, postam fotos e listas de interesses (SANTOS, 2014). Até o ano de 2010, era tida como a rede social mais utilizada mundialmente e, em sua maioria, por estudantes universitários (PATRÍCIO; GONÇALVES, 2010).

Patrício e Gonçalves (2010) e Santos (2014) basearam-se nas constatações encontradas nos estudos realizados por, Kelly (2007), em que restou comprovado que o Facebook não é apenas um canal de comunicação e compartilhamento, mas também um meio educativo. Em se tratando de um meio educativo, pode-se inferir que diversas instituições de ensino devem fazer parte desse meio digital para promover sua imagem e para atingir os estudantes que fazem uso dessa rede. Segundo Santos (2014), as empresas criam uma fanpage disponível para organizações com ou sem fins lucrativos, onde publicam fotos, vídeos e textos para se promoverem, com o propósito de atrair e interagir com seus clientes. A disseminação do conteúdo na rede acontece por intermédio das reações, comentários e compartilhamentos. 
Apesar de o Facebook ser uma das ferramentas mais utilizadas quando se trata de redes sociais, também pode-se observar o crescimento da importância do Instagram dentro dos processos comunicativos. O Instagram foi criado em 2010 pelo norte-americano Kevin Systrom e pelo brasileiro Mike Krieger, formados pela Universidade Stanford. No início, o aplicativo só era disponibilizado para o sistema operacional iOS, da Apple; em 2012, chegou aos dispositivos com sistema operacional Android, do Google e, não muito tempo depois, a empresa desenvolvedora do aplicativo foi comprada por Mark Zuckerberg, o criador do Facebook (OLIVEIRA, 2014). Conforme Oliveira (2014), para utilizar o Instagram, o usuário deve registrar-se, criando um perfil que possibilita tirar fotos, fazer vídeos curtos e editá-los com diversos efeitos. Silva (2012) afirma que essa ferramenta mistura conceitos de rede social com câmera fotográfica, proporcionando a exposição e compartilhamento do cotidiano, das relações de consumo e das experiências vividas pelo sujeito. Baseado nisso, a exposição no Instagram busca responder à premissa: "o que você está fazendo (vendo) agora?”.

Simplificando os conceitos, pode-se explicar o Instagram como um aplicativo que gera a interação entre os usuários por meio da postagem de fotos e vídeos em prol de saciar o desejo de ver e de ser visto pelos outros. Da mesma maneira que o Facebook, essa rede social também pode ser utilizada por empresas que queiram divulgar seu trabalho e atrair clientes (OLIVEIRA, 2014).

Uma das formas de realizar a divulgação desejada pelas empresas, nas redes sociais, é por meio do uso de símbolos como hashtag, por exemplo, durante as postagens, quando é inserido o símbolo “\#” seguido de uma ou mais palavras, funcionando como uma espécie de "etiqueta" ou indexador de conteúdo, que proporciona aos usuários seguirem informações específicas sobre determinado assunto ou evento por meio de hiperlinks que redirecionam o internauta para um aprofundamento que vai além do exposto nas publicações (SILVA; VIEIRA; SCHNEIDER, 2010).

De acordo com Oliveira (2012), o dimensionamento de interatividade entre as páginas de redes sociais e os usuários pode ser classificado em três níveis: baixa, média e alta interatividade. A baixa interatividade é definida quando os usuários não participam da construção do conteúdo em si; na média interatividade, há a construção de conteúdo, mas essas ações não são visualizadas pelos outros usuários; na alta interatividade, há a visibilidade total das ações realizadas pelos usuários.

Baseando-se na classificação proposta por Oliveira (2012) e pelos conceitos de 
Facebook e Instagram cedidos pelos demais autores, pode-se perceber que ambas as ferramentas apresentam o nível de interatividade entre média e alta com os usuários: alta, pois tudo que é postado pelos usuários pode ser visualizado pelos demais, e média pelo fato de que, para haver a visualização por terceiros, é necessário que a sua política de privacidade permita o acesso a esse conteúdo. A política de privacidade pode variar, permitindo que qualquer um veja o que foi postado ou dando essa permissão apenas para as pessoas que fazem parte da sua rede de contatos. Sabendo-se como funcionam as duas redes sociais em questão e suas características, a próxima seção traz a utilização dessas redes sociais dentro do contexto do marketing educacional, ou seja, como as instituições de ensino podem fazer uso dessas ferramentas em prol de seus objetivos organizacionais.

\subsection{Marketing educacional}

Tradicionalmente, as IES aguardavam pela demonstração de interesse de estudantes para darem início ao relacionamento de troca de informações entre ambos, fato que acontecia por não haver uma preocupação com esse tipo de ramo de negócio, não existir muita concorrência entre as instituições e, também, pelo aprendizado e a qualidade serem assuntos indiscutíveis, findando em uma imagem intocável das instituições. Com o tempo, essa prática sofreu alterações, as instituições passaram a agir como empresas em busca de um diferencial que as tornassem sólidas no mercado, para isso, se comprometeram em analisar o mercado e identificar a demanda existente em prol de uma espécie de comunicação, podendo influenciar a preferência dos estudantes no mercado, fazendo uso de estratégias para fidelizar seu público (KOTLER; FOX, 1994; SILVA, 2009).

Dentro deste ambiente, as instituições de ensino superior buscam encontrar soluções para problemas como: manter seus níveis de matrículas, a queda em número de potenciais alunos, evitar a redução de seus padrões, entre outros. Para tal objetivo, optaram pela adoção do marketing para garantir a eficácia no recrutamento e divulgar seus diferenciais, infraestrutura e os valores defendidos, já que, possuem uma relação de dependência desse mercado. (KOTLER; FOX, 1994). Essa relação de dependência pode ser evidenciada devido a prestação dos serviços educacionais e dos relacionamentos provenientes dela, tanto com alunos e ex- alunos, pois são frequentes e duradouros (MASSAINE, 2010).

O marketing aplicado às instituições de ensino superior é uma atividade central 
focada em atender de forma eficaz alguma área de necessidade humana, normalmente utilizado para o estabelecimento de um relacionamento positivo com o seu público. Para a sua realização e aplicação adequada, torna-se necessário seguir algumas etapas do planejamento de marketing, como conhecer o mercado em que se está inserido, atrair recursos, transformando-os em ideias e serviços apropriados para a aquisição de vários públicos consumidores, se dispondo a uma relação de troca com seus participantes para atingir seus objetivos organizacionais iniciais no planejamento de marketing (KOTLER; FOX, 1994).

Apesar da importância do marketing para as instituições, na maioria das vezes, essa atividade fica restrita a campanhas sazonais, como ocorre durante os períodos prévestibulares, por exemplo. Existem várias estratégias que podem alterar essa realidade, entre elas, a utilização de redes sociais, ou seja, fazer parte de plataformas como Facebook, Instagram, entre outras, em prol de interagir e se comunicar com o público presente nessas redes. Para tanto, é necessário que essas estratégias estejam vinculadas com um planejamento bem estruturado, capaz de influenciar em seu crescimento como instituição e sua imagem (MARTINS; MENEZES; JUSTINIANO, 2011). Internalizado ao planejamento deve estar estratégias de monitoramento, servindo para captar a repercussão junto ao público e identificar e definir decisões futuras (IACOVELO, 2017), ou seja, avaliar as interações, responder aos comentários, tirar dúvidas, atualizar periodicamente, utilizar a comunicação para a criação de um relacionamento.

À vista disso, é possível perceber o marketing como uma atividade complexa e de muita abrangência dentro de uma empresa ou instituição de ensino, para tanto, sendo necessário, para seu melhor desempenho, possuir entendimento sobre marketing e compreender o segmento da educação (COLOMBO et al., 2005).

\section{Método}

O trabalho classifica-se, quanto à abordagem do problema, como uma pesquisa qualitativa (DIEHL; TATIM, 2004) e como descritiva (GIL, 2002). Quanto ao procedimento técnico, o estudo partiu de uma pesquisa de fontes secundárias, que, segundo Cunha (2001) é caracterizada por ser desenvolvida com base em material já existente. Além disso, fez-se a aplicação de um questionário composto por uma série ordenada de perguntas abertas (MARCONI; LAKATOS, 2003). A aplicação do questionário aconteceu 
com a pessoa responsável pelo setor de comunicação e mídias sociais de cada uma das duas IES, sendo este composto por nove perguntas abertas, que permitiram aos participantes cederem informações sobre o comportamento adotado nas redes sociais, padrões de publicações, opiniões sobre o uso desses meios, entre outras.

A pesquisa foi realizada com duas IES do Rio Grande do Sul, ambas universidades, sendo uma pública e a outra privada, e levou em consideração apenas o campus sede de cada uma delas. A universidade pública encontra-se localizada na cidade de Santa Maria e possui o total de cinco campi, em cidades diferentes já, a universidade privada localiza-se em Passo Fundo, e possui o total de 12 unidades acadêmicas distintas, distribuídas em sete cidades $^{3}$. Os dados utilizados na pesquisa foram coletados por meio de duas redes sociais de cada uma das IES, sendo elas, o Facebook e o Instagram. A análise desses dados classifica-se como uma análise de conteúdo que, conforme Bardin (1977), consiste em técnicas que descrevem conteúdos emitidos no processo de comunicação e proporcionam o levantamento de indicadores (quantitativos ou não), permitindo a inferência de conhecimentos.

As informações necessárias para a pesquisa foram coletadas durante o período do mês de março a maio de 2018 e levaram em consideração todas as publicações realizadas por ambas IES desde o mês de janeiro até maio do mesmo ano. A coleta abrangeu os seguintes aspectos ou categorias de análise: frequência de postagens, conteúdo divulgado, interação com o público e a propagação das publicações (número de curtidas/reações, compartilhamentos e comentários em ambas as redes sociais).

A análise das redes sociais levou em consideração os seguintes quesitos no momento da coleta de dados: total de seguidores, total de curtidas (na fanpage), tipo de linguagem, público-alvo, frequência de postagem, conteúdo divulgado, interação/relacionamento, comentários, curtidas/reações e compartilhamentos. Sendo que, não, necessariamente, todos os quesitos tenham sido abordados nas duas redes sociais, pois há alterações de uma para a outra como, por exemplo, o total de curtidas da fanpage e o total de compartilhamentos de uma postagem, pois são informações que o Instagram não utiliza.

A frequência das postagens verificou a periodicidade em que ocorrem as publicações realizadas nas redes sociais pelas IES. O quesito conteúdo foi avaliado conforme o tipo de linguagem utilizada (formal ou informal); o tipo de informação

\footnotetext{
${ }^{3}$ Optou-se por questões éticas em preservar o nome das IES pesquisadas.
} 
divulgada, se corresponde a informações de cunho acadêmico ou voltadas para a comunidade; o público-alvo; entre outras categorias que tiveram sua relevância percebida durante a análise das redes sociais. A interação/relacionamento foi medida conforme a percepção de contato das IES para com as pessoas envolvidas nas redes sociais e como elas tentam se comunicar no meio virtual. Já a respeito da propagação das postagens, esta foi verificada pelo tema ou características que geraram maior número de compartilhamentos, curtidas/reações e comentários no Facebook, e o maior número de curtidas e comentários via Instagram. Dessa forma, pretendeu-se identificar o comportamento e a influência da utilização das redes sociais para o marketing digital de Instituições de Ensino Superior (IES) no Rio Grande do Sul, ao levar em consideração quesitos como comunicação, interação e divulgação da imagem institucional.

\section{Discussão e Resultados}

Nesta seção apresentam-se informações acerca da caracterização do ambiente estudado e os resultados obtidos na aplicação da pesquisa, por meio da coleta de dados realizada nas redes sociais de duas Instituições de Ensino Superior (IES) gaúchas, assim como, pela aplicação do questionário, A coleta de dados partiu do objetivo de, por meio da análise do comportamento das IES no meio virtual, especificadamente, nas redes sociais (Facebook e Instagram), identificar a influência que essas redes proporcionam para a realização da comunicação entre as variáveis e divulgação da imagem institucional, conforme conceitos do marketing digital.

\subsection{Caracterização do ambiente estudado}

As duas Instituições de Ensino Superior (IES) estão localizadas no estado do Rio Grande do Sul, definidas como universidades, sendo uma pública localizada na região central do estado e, a outra, privada na região norte. Ambas IES possuem mais de um campus ou unidades acadêmicas, mas para a realização da pesquisa foi determinado o foco no campus sede de cada uma das instituições.

A instituição pública, fundada no ano de 1960, possui cinco campi em cidades diferentes no estado do Rio Grande do Sul, sendo elas: Cachoeira do Sul, Frederico Westphalen, Palmeira das Missões, Santa Maria e Silveira Martins. Possui um corpo 
acadêmico composto por 20.551 alunos, distribuídos em um total de 128 cursos (RUF, 2017). O foco da pesquisa deteve-se ao campus sede que situa-se na cidade de Santa Maria. Há 58 anos construindo histórias na cidade, esta IES também optou por criar histórias no meio virtual, encontra-se com uma fanpage principal no Facebook desde o ano de 2012 e, no Instagram, mais recentemente, desde 2016.

A instituição privada, fundada em 1968, detém de 12 unidades acadêmicas distintas espalhadas pelas seguintes cidades do Rio Grande do Sul: Carazinho, Casca, Lagoa Vermelha, Palmeira das Missões, Passo Fundo, Sarandi e Soledade. A instituição conta com 17.150 alunos alocados em 100 cursos diferentes (RUF, 2017). Para a realização da pesquisa, foi considerado apenas o seu campus sede, localizado na cidade de Passo Fundo. Assim, como a IES de localizada em Santa Maria, com o tempo, devido à era da informação e comunicação e da facilidade de relacionamentos com seu público-alvo, a IES situada em Passo Fundo também ingressou no meio virtual, estando presente no Facebook desde o ano de 2011 e no Instagram desde 2012.

Conforme Ranking Universitário Folha (RUF), que é uma avaliação que ocorre anualmente do ensino superior do Brasil, 195 universidades brasileiras, públicas e privadas, foram avaliados conforme cinco quesitos: pesquisa, internacionalização, inovação, ensino e mercado. A instituição pública, após a realização dessa avaliação, foi classificada em $17^{\circ}$ lugar e, a instituição privada foi a $73^{\circ}$ colocada no ranking (RUF, 2017). Após a caracterização das IES que foram analisadas, o próximo item apresenta os resultados provenientes da coleta de dados que ocorreu nas redes sociais (Facebook e Instagram) somadas ao questionário aplicado.

\subsection{Análise dos resultados em relação à pesquisa nas redes sociais}

As duas instituições de ensino superior, pública e privada, diante do avanço das Tecnologias de Informação e Comunicação, da internet e das mídias sociais, sentiram a necessidade de ingressar no mundo digital. A representante da IES privada argumenta sobre essa questão:

Como isso foi a 08 anos atrás, não tínhamos muitas opções e nem um planejamento rígido sobre isso. Começamos com as mais populares [...], e á medida que as demais foram surgindo, avaliamos suas características e aderimos caso fossem compatíveis com as nossas propostas de comunicação [...]. Na época, vislumbrávamos que as redes poderiam ser uma potente forma de relacionamento da instituição com seus públicos. Elas eram consideradas 
espaços jovens e informais, e pareciam uma boa oportunidade de aproximar a instituição dos alunos, criar intimidade, fortalecer laços e adicionar informalidade nos processos já institucionalizados de uma Universidade com 42 anos, e com, na época, 22 mil alunos.

O discurso da IES privada revela o seu posicionamento e a sua percepção em relação às novidades que surgem no mercado, percebendo o potencial de ferramentas alternativas que podem contribuir para suas estratégias organizacionais ou para a definição de novas. Já a instituição pública, fez as seguintes afirmações:

\begin{abstract}
A decisão [de se fazer presente nas redes sociais] foi tomada por outra gestão da Reitoria, da Coordenadoria de Comunicação e da Agência de Notícias em 2011, momento em que as redes sociais começaram a contribuir para os acessos do site institucional. O início foi focado na reverberação de conteúdo do site e também em coberturas de grandes eventos na instituição. Não [houve nenhuma pesquisa para definir qual rede social se encaixaria melhor aos objetivos organizacionais]. Mas as pessoas que cuidaram e cuidam das redes sociais sempre foram pessoas ligadas às mídias digitais [...].
\end{abstract}

Diante dessas informações, percebeu-se que as instituições aderiram às redes sociais com objetivos diferentes, mas, com o passar do tempo, se potencializou na aproximação ou criação de relacionamento com a sociedade de forma geral. Segundo a instituição pública: "A sociedade conversa com as instituições a partir de vários meios e as mídias sociais estão entre os mais utilizados”. Já, a instituição privada dá um exemplo do nível que esse relacionamento com a sociedade pode atingir, segundo ela: "A instituição tem hoje mais ou menos 17.500 alunos, mas quase 100.000 curtidores. Ou seja, a imensa maioria dos nossos amigos, nas redes, não são [nossos] alunos". Sendo assim, corroborando para assertiva de que as redes sociais colaboram para a criação e manutenção de relacionamentos em redes.

Para facilitar a descrição das características utilizadas na análise e a compreensão de como isso se procede em cada rede social, a análise das instituições dividiu-se de acordo com a rede social ponderada, assim como demonstrado nos itens a seguir.

\title{
4.2.1 Percepção das fanpages do Facebook
}

Ao analisar o Facebook da instituição pública, foi possível inferir que esta rede social possuía, aproximadamente, 84.450 pessoas seguindo ${ }^{4}$ sua fanpage, e 84.750 pessoas

\footnotetext{
${ }^{4}$ Ação que resulta em receber atualizações sobre a Página no Feed de Notícias (FACEBOOK, 2018).
} 
curtindo $^{5}$ a página desta IES. Já a instituição privada possuía, aproximadamente, 98.720 pessoas seguindo a fanpage e, em torno de, 99.305 pessoas curtindo a página desta IES $^{6}$. O resultado desse montante dá-se pelo somatório de comunidade acadêmica e sociedade em geral que, por mais que não façam parte desse grupo que vivência a vida acadêmica, ainda assim, fazem uso do campus para aproveitar um final de semana ou participar de eventos que nele são sediados. Para atingir esses públicos, bem numerosos, as instituições optaram por uma linguagem mais informal/coloquial, de forma que possa haver a comunicação, ou seja, a emissão de uma informação e o entendimento dela por parte dos usuários, utilizando artifícios como emojis, GIFs, fotos, vídeos e links.

Quanto à frequência de postagem, constatou-se que as mesmas acontecem diariamente, duas/três vezes por dia, sendo exceções os dias em que não há nenhuma publicação, pois, trata-se da fanpage principal das duas IES no Facebook, englobando publicações de todos os campi que compõem as instituições. Ambas as instituições afirmaram, por intermédio do questionário, que se baseiam em padrões para postagens, realizando-as em momentos de pico, isto é, que proporcionem maior visualização, e que consideram, também, a quantidade de publicações realizadas, exceto, durante campanhas institucionais e grandes eventos. Segundo a instituição pública, eles possuem cuidados com a quantidade de postagens, para que as publicações não sejam penalizadas pelos algoritmos $^{7}$ do Facebook, e, geralmente, realizam dois posts diários. Já a instituição privada, deixou claro que segue, por regra, um padrão de três postagens por dia nessa rede social.

A respeito dos conteúdos publicados, estes possuem caráter informativo e, decorrem da divulgação de palestras atribuída à cursos de graduação e pós-graduação, destinada à qualificação de professores, atividades, oficinas, homenagem em dias específicos, períodos pré-vestibulares, visitas técnicas para escolas de ensino fundamental e médio, trabalhos realizados pelos estudantes e, também, através do feedback de todos esses acontecimentos. As temáticas abordadas variam de acordo com o objetivo e públicoalvo que determinada atividade se propõe a atingir, levando em consideração assuntos específicos para cursos de graduação e pós-graduação e, bem como, de interesse social.

O relacionamento nessa rede social se constrói através da interação, quando após a

\footnotetext{
${ }^{5}$ Ação de apoio e interesse pelo conteúdo da página. Esta ação é exibida como curtida na seção Sobre do perfil dessa pessoa (FACEBOOK, 2018).

${ }^{6}$ Informações obtidas na data de 11 de junho de 2018.

${ }^{7}$ A alteração de algoritmo diminuiu o alcance das publicações das fanpages, em prol de priorizar o que é importante para seus usuários, isto é, favorece posts de amigos, familiares e grupos.
} 
realização de uma publicação, os usuários que curtem ou seguem as páginas comunicam-se com as instituições por intermédio de comentários, compartilhamentos e reações. Os comentários, em sua maioria, são de usuários marcando outros usuários, para que estes tomem conhecimento do que está sendo divulgado, os demais se enquadram em elogios às iniciativas, dúvidas, opiniões contrárias e críticas ao que foi proposto. Os compartilhamentos ajudam a expandir o alcance das publicações e, as reações, demonstram o quanto aquela publicação impactou para os usuários.

Outros fatores foram perceptíveis dentro da análise dessa rede social como, por exemplo: o uso de hashtag, tanto pelas instituições quanto alunos, que funciona como indexador do conteúdo publicado; as publicações em sua maioria são realizadas diretamente pela fanpage oficial das instituições, mas, também, se utilizam do compartilhamento de postagens já realizadas em outros perfis secundários, ampliando a cadeia de divulgação; dependendo do que é exposto, as instituições utilizam seus sites para redirecionar os interessados em obter mais informações; a quantidade de comentários, compartilhamentos e reações é maior dependendo do que é divulgado nessa rede social, a título de exemplo, postagens com temas polêmicos ou que interfiram diretamente a vida da comunidade acadêmica. Assim como demonstrado no Quadro 2, onde consta de forma resumida os dados obtidos na análise dessa rede social.

\begin{tabular}{|c|c|c|}
\hline CARACTERÍSTICAS & IES PÚBLICA & IES PRIVADA \\
\hline Total de Seguidores & 84.450 & 98.720 \\
\hline Total de Curtidas (Page) & 84.750 & 99.305 \\
\hline Tipo de Linguagem & \multicolumn{2}{|c|}{ Linguagem informal. } \\
\hline Público-Alvo & \multicolumn{2}{|c|}{ Comunidade acadêmica e sociedade em geral. } \\
\hline Frequência de Postagem & \multicolumn{2}{|c|}{$2 / 3$ vezes por dia. } \\
\hline Conteúdo Divulgado & \multicolumn{2}{|c|}{ Específicos para cursos e de interesse social. } \\
\hline Relacionamento & \multicolumn{2}{|c|}{$\begin{array}{c}\text { Através da interação por meio de reações, comentários e } \\
\text { compartilhamentos. }\end{array}$} \\
\hline Prática Usual & \multicolumn{2}{|c|}{ Uso de hashtag. } \\
\hline Dificuldade Enfrentada & \multicolumn{2}{|c|}{ Mudança no algoritmo. } \\
\hline
\end{tabular}

Quadro 1 - Categorias de análise do Facebook de ambas as Instituições - pública e privada no RS. Fonte: Elaborado pelos autores.

Por conta disso, infere-se que o Facebook apresenta um número elevado de usuários que seguem e curtem a fanpage das duas IES, mas que estes não representam mais 
uma quantia substancial, devido à mudança de algoritmo que foi imposta a essa rede social. A alteração funcionou como uma espécie de bloqueio para as postagens das instituições, pois suas publicações não alcançam mais todos os usuários pertencentes àquela rede, uma vez que, a prioridade passou a ser de postagens realizadas por amigos, família e grupos.

Uma das maneiras encontradas para estimular o nível de propagação e conhecimento das publicações, deu-se pelo fato de que os comentários, antes de opiniões e críticas, cederam espaço para comentários em que os usuários marcam outros, para que estes tomem conhecimento sobre certa publicação. Além dessa estratégia, tem-se usado, também, o compartilhamento de publicações como maneira de aumentar o nível de propagação das publicações.

\subsubsection{Percepção dos perfis do Instagram}

Uma diferença entre as duas redes sociais que é bem evidente é o total de seguidores, a instituição pública conta com 11,3 mil seguidores e a instituição privada com 11,8 mil em seus respectivos perfis do Instagram ${ }^{8}$. Para se comunicar com seus públicos, que são compostos por comunidade acadêmica e sociedade em geral, as instituições fazem uso de linguagem coloquial e, também, de linguagem não-verbal que é a característica mais marcante nesta rede social, utilizando, também, recursos como emojis, GIFs e links.

A utilização dessa rede social possui um caráter diferente para cada uma das duas instituições. A instituição pública, por exemplo, mantém seu perfil com publicações que acontecem com certo intervalo de tempo entre uma e outra, contando com a participação dos usuários, ou seja, praticamente todas as fotos divulgadas são tiradas pelos próprios seguidores e frequentadores da instituição, que registram conforme seu ponto de vista determinada imagem, contribuindo para o relacionamento de interação entre IES e seguidores. Conforme a instituição: “As imagens podem ser produzidas pela Agência de Notícias ou por internautas que usam as tags \#UFSM ou de alguma campanha. Nossa proposta é postar uma foto por dia". Segundo a responsável pelo setor de comunicação da IES, essa abordagem estimula à cultura participativa.

Os conteúdos dessas divulgações, normalmente, estão direcionados para paisagens, não abrangendo informações educacionais destinadas a áreas específicas e, apostam muito no uso de hashtag que funcionam como palavras chaves para serem utilizadas como um

\footnotetext{
${ }^{8}$ Informações obtidas na data de 11 de junho de 2018.
} 
link para determinado assunto. Apesar de haver essa interação, isso não significa que os seguidores promovem grande número de curtidas ou comentários em todas as publicações.

Ao longo da análise, pode-se perceber que imagens com características mais profissionais, em termos de qualidade, ou com animais acabavam por receber mais curtidas e comentários elogiando ou questionando onde aquele lugar em questão se localizava no campus.

Já, a instituição privada segue a mesma linha de conteúdos divulgados que no Facebook, ou seja, faz diariamente a divulgação de eventos com ou sem restrição de público, informações destinadas a cursos específicos, período pré-vestibular, projetos de extensão, só que de maneira mais simplificada, redirecionando o interessado a obter mais informações em outra rede social ou no site da instituição. A interação entre instituição e seguidores acontece por meio dos comentários e das curtidas e representa, quantitativamente, um número maior que o apresentado na instituição pública. Assim como demonstrado no Quadro 3, o qual apresenta de forma sintetizada os resultados encontrados por meio da análise das redes sociais como, pela aplicação do questionário.

\begin{tabular}{|c|c|c|}
\hline CARACTERÍSTICAS & IES PÚBLICA & IES PRIVADA \\
\hline Total de Seguidores & $11,3 \mathrm{mil}$ & $11,8 \mathrm{mil}$ \\
\hline Tipo de Linguagem & \multicolumn{2}{|c|}{ Linguagem informal e não-verbal. } \\
\hline Público-Alvo & \multicolumn{2}{|c|}{ Comunidade acadêmica e sociedade em geral. } \\
\hline Frequência de Postagem & Proposta de uma foto por dia. & $2 / 3$ vezes por dia. \\
\hline Conteúdo Divulgado & Fotos tiradas por usuários. & $\begin{array}{l}\text { Específicos para cursos e de } \\
\text { interesse social. }\end{array}$ \\
\hline Relacionamento & $\begin{array}{c}\text { Estimula a cultura participativa e } \\
\text { por meio de curtidas e } \\
\text { comentários. }\end{array}$ & $\begin{array}{l}\text { Através da interação por meio } \\
\text { de curtidas e comentários. }\end{array}$ \\
\hline Prática Usual & \multicolumn{2}{|c|}{ Uso de hashtag. } \\
\hline
\end{tabular}

Quadro 2 - Categorias de análise do Instagram de ambas as Instituições - pública e privada no RS. Fonte: Elaborado pelos autores.

Após a análise dos dados coletados e das respostas obtidas no questionário, foi possível inferir que o a quantidade de seguidores e amigos não significa o mesmo volume de interação. A instituição privada afirma: “Temos um público de quase 12 mil seguidores no instagram e quase 100.000 no facebook. [...] Proporcionalmente a porcentagem de interação no instagram é bem maior do que no facebook". Sendo assim, o Instagram foi eleito pelas duas instituições como a rede social que mais proporciona interação dos 
usuários.

Outro ponto interessante sobre a busca de interação das duas IES com a comunidade acadêmica e sociedade em geral, é que durante o período de férias, período em que as universidades não têm a presença constante de alunos, professores e funcionários, ambas as instituições utilizam as redes sociais, seja pelo Facebook ou Instagram, para chamar seus seguidores e amigos para visitarem seus campi, museus e demais espaços, incentivando a fazerem parte desse ambiente independente do ano letivo ter começado ou não.

Nesse sentido, pode-se presumir que o Instagram, apesar de não ser a rede com maior número de seguidores, é a rede social que mais proporciona e estimula a comunicação e o relacionamento entre IES e usuários. Devido ao fato de que suas publicações utilizam mais da participação dos usuários, assim como é o caso da instituição pública, que utiliza as fotos tiradas por eles ou, da instituição privada que faz uso de seus eventos para divulgar a sua imagem enquanto IES. Apesar disso, foi notório o fato de que divulgações que contavam com fotos de maior qualidade, fotos de animais ou de eventos muito prestigiados, resultavam em maior impacto e adesão.

De um modo geral, a pesquisa proporcionou uma visão generalizada sobre como duas IES gaúchas se comportam em redes sociais especificas, assim como, possíveis benefícios que acabam obtendo por estarem presentes nesse meio. Sendo papel das instituições definirem quais estratégias serão usadas, de modo, a utilizar essas redes de relacionamento de forma eficiente. A seguir, apresentam-se as considerações finais sobre o estudo.

\section{Considerações Finais}

Nesse trabalho objetivou-se compreender o comportamento de duas instituições gaúchas de ensino superior nas redes sociais (Facebook e Instagram), e a influência que essas mídias configuram no marketing digital. Em virtude dos dados obtidos e analisados por meio da realização da pesquisa, é possível afirmar que as ferramentas utilizadas para a coleta dos dados, tanto a análise das redes sociais quanto o questionário, foram satisfatórias, pois permitiram a visualização do comportamento dessas duas instituições em duas redes sociais distintas como, também, a influência que desempenham sobre o marketing digital, em relação ao prisma de comunicação e relacionamento. 
Durante a realização da coleta de dados, tornou-se perceptível a diferença existente entre os objetivos de cada rede social para ambas IES e a importância que exercem. De forma geral, o Facebook funciona e é utilizado pelas instituições, como principal porta-voz para qualquer divulgação de eventos, sejam eles destinados aos alunos ou não, e demais informações que possam interessar às pessoas que estão presentes e que seguem aquela página por algum motivo. E, o Instagram é mais uma rede social voltada para a divulgação de imagens e da imagem das instituições.

A respeito da fanpage do Facebook, o estudo em questão demonstrou que o número de seguidores e de pessoas que curtem a página não representa uma variável suficiente para determinar o nível de interação existente entre instituições e usuários. Essas interações e relacionamentos, a partir do momento que estão inseridos em uma rede social, devem levar em consideração as condições que ali são ofertadas. Nesse caso, o Facebook sofreu a alteração de seu algoritmo, fator que surpreendeu a todos, pois o raio de propagação das publicações sofreu reduções, não atingindo mais toda a base de fãs que as páginas possuíam.

Essas situações refletem no relacionamento e comunicação entre IES e usuários. Se essa era a principal rede social utilizada pelas instituições, cabe agora aos profissionais responsáveis migrarem seus esforços para uma rede que proporcione retorno sobre aquilo que foi postado ou que, pelo menos, exerça e dê condições das instituições exercerem seus papeis enquanto comunicadoras sociais ou divulgadoras da sua própria imagem. Por conta disso, percebeu-se a importância de possuir profissionais capacitados, que tenham conhecimento sobre a publicidade online, na qual se insere o marketing digital, pois esse profissional deverá estruturar estratégias em prol de cada vez mais estar e fazer-se presente no meio digital, de forma que as IES consigam se comunicar com os demais usuários.

Os resultados encontrados através da análise do Instagram refletem que a interação nessa rede social cresceu exponencialmente, devido à alteração do algoritmo do Facebook. O Instagram, embora com percentual bem menor de seguidores, é a rede social que mais tem proporcionado a comunicação entre instituições e usuários, pois não sofre com a penalização do algoritmo.

O marketing digital, enquanto estratégia, trabalha a questão de atitudes que as empresas devem utilizar para fidelizar seus clientes, bem como, para realizar a manutenção da sua imagem corporativa. Através do estudo foi possível visualizar o interesse das instituições de proporcionarem que as informações cheguem até seus usuários, a 
preocupação de manterem um relacionamento e comunicação com eles, de modo a facilitar, até mesmo, processos que seriam mais burocráticos se fossem tratados pessoalmente. Já, sobre a questão de reter novos alunos, percebeu-se que estar nas redes sociais não é fator condicionante para isso, mas que a divulgação da imagem e a facilidade da comunicação, despertam interesse sobre instituições que estão por mais de 50 anos exercendo suas atividades no mercado da educação.

O posicionamento das instituições de ensino superior dentro das redes sociais cede a elas o espaço de assumirem sua própria voz e se responsabilizarem por todas as informações divulgadas a seu respeito, bem como, pela sua imagem em si. A instituição, assim como qualquer empresa, que não faça parte desse meio digital, abre precedente para que a sua imagem e postura diante da sociedade seja definida por aquilo que dizem sobre ela naquele espaço. Sendo assim, é muito arriscado deixar que a imagem institucional de uma empresa seja definida apenas pelo que os outros veem, boa parte da imagem de uma instituição é determinada pela sua capacidade de comunicação com o público, pelo que ela se diz ser e pelos seus propósitos, fatores que só as próprias instituições podem oferecer aos seus usuários.

Por fim, conclui-se que as redes sociais, enquanto ferramentas que auxiliam e influenciam o marketing digital, tornam-se atrativas para as empresas e, nesse caso, instituições de ensino superior, devido à visibilidade e manutenção da imagem institucional e de relacionamentos, que o meio digital proporciona por intermédio da comunicação e dos relacionamentos interativos, colaborando, assim, para que as IES comportem-se de modo a priorizar a distribuição de informação, o diálogo e o engajamento dos públicos a sua volta.

\section{REFERÊNCIAS}

BARDIN, L. Análise de conteúdo. Lisboa: Edições 70, 1977.

BRANDÃO, V. C. Comunicação e marketing na era digital: a internet como mídia e canal de vendas. Revista Intercom - RBCC, Campo Grande. 2001. Disponível em: <http://www.portcom.intercom.org.br/pdfs/63367481050614301224660314786789274330 .pdf>. Acesso em: 14 abr. 2018.

CIRIBELI, J. P.; PAIVA, V. H. P. Redes e mídias sociais na internet: realidades e perspectivas de um mundo conectado. Revista Mediação, Belo Horizonte, v. 13, n. 12, jan./jun. 2011. Disponível em: <http://www.fumec.br/revistas/mediacao/article/view/509/504>. Acesso em: 06 abr. 2018.

COLOMBO, S. S. (Org.) et al. Marketing educacional em ação: estratégias e ferramentas. 
Porto Alegre: Bookman, Artmed, 2005.

CRUZ, C. A. B.; SILVA, L. L. Marketing digital: marketing para o novo milênio. Revista Científica do ITPAC, Araguaína, v. 7, n. 2, abr. 2014. Disponível em: <https://www.itpac.br/arquivos/revista/72/1.pdf>. Acesso em: 14 out. 2017.

CUNHA, M. B. Para saber mais: fontes de informação em ciência e tecnologia. Brasília: Briquet de Lemos/ Livros, 2001. 168 p. Disponível em: <http://www.periodicos.ufpb.br/index.php/pgc/article/viewFile/12466/8031>. Acesso em: 16 abr. 2018.

DIEHL, A. A.; TATIM, D. C. Pesquisa em ciências sociais aplicadas: métodos e técnicas. São Paulo: Prentice Hall, 2004.

FACEBOOK. Central de ajuda: o que significa quando uma pessoa curte ou segue uma página. 2018. Disponível em: <https://www.facebook.com/help/171378103323792>. Acesso em: 18 jun. 2018.

FACEBOOK. Central de ajuda: como faço para ver informações sobre stories na minha página. Disponível em: <https://www.facebook.com/help/249460088951927?helpref=search\&sr=1\&query=stories >. Acesso em: 20 jun. 2018.

GABRIEL, M. Marketing na era digital: conceitos, plataformas e estratégias. São Paulo: Novatec, 2010. Disponível em: <http://www.ebah.com.br/content/ABAAAgobIAJ/marketing-na-era-digital-marthagabriel-completo>. Acesso em: 30 ago. 2017.

GIL, A. C. Como elaborar projetos de pesquisa. 4. ed. São Paulo: Atlas, 2002. Disponível em: $\quad<$ http://www.urca.br/itec/images/pdfs/modulo\%20v\%20\%20como_elaborar_projeto_de_pesquisa_-_antonio_carlos_gil.pdf $>$. Acesso em: 08 nov. 2017.

IACOVELO, M. T. Uso e repercussão das mídias sociais em instituições de ensino superior privadas de Goiás. 2017. Dissertação (Pós-Graduação em Administração) Centro Universitário Alves Faria, Goiânia, 2017. Disponível em: $<$ http://webcache.googleusercontent.com/search?q=cache:hHzg42n_YsEJ:www.unialfa.co m.br/lib/download.php\%3Farq\%3Darqs/biblioteca/digital/178.pdf\%26nome\%3Duso-erepercusso-das-mdias-sociais-em-instituies-de-ensino-superior-privadas-degois.pdf $+\& c d=1 \& h l=p t-B R \& c t=c l n k \& g l=b r>$. Acesso em: 23 maio 2018.

KOTLER, P. Marketing 3.0: as forças que estão definindo o novo marketing centrado no ser humano. Tradução Ana Beatriz Rodrigues. Rio de Janeiro: Elsevier, 2012. Disponível em: <http://www.fcap.adm.br/wp-content/uploads/2014/07/Marketing-3-PhilipKotler.pdf $>$. Acesso em: 30 ago. 2017.

KOTLER, P.; FOX, K. F. A. Marketing estratégico para instituições educacionais. São Paulo: Atlas, 1994. 
LEMES, L. B.; GHISLENI, T. S. Marketing digital: uma estratégia de relacionamento de marca. Revista Intercom - RBCC, Santa Cruz do Sul. 2013. Disponível em: <http://www.portalintercom.org.br/anais/sul2013/resumos/R35-1737-1.pdf>. Acesso em 14 out. 2017.

MARCONI, M. A.; LAKATOS, E. M. Fundamentos da metodologia científica. 5. ed. São Paulo: Atlas, 2003. Disponível em: $<$ https://docente.ifrn.edu.br/olivianeta/disciplinas/copy_of_historia-i/historia-ii/china-eindia>. Acesso em: 18 jun. 2018.

MARTINS, J. V. G.; MENEZES, R. M. T.; JUSTINIANO, L. S. Atuação do departamento de marketing em uma instituição de ensino superior - IES. Revista Gestão Universitária na América Latina - GUAL, v. 4, n. 2, p. 110-122, mai./ago. Florianópolis. 2011. Disponível em: <http://www.redalyc.org/html/3193/319327511007/>. Acesso em: 22 mai. 2018.

MASSAINE, E. O. Marketing educacional: os desafios de uma instituição de ensino para conquistar e manter alunos. 2010. Trabalho de Conclusão de Curso (Bacharel em Administração) - Universidade São Francisco, Bragança Paulista, 2010. Disponível em: $<$ https://lyceumonline.usf.edu.br/salavirtual/documentos/1985.pdf $>$. Acesso em: 20 mai. 2018.

MONDINI, L. C. et al. Redes sociais digitais: uma análise de utilização pelas instituições de ensino superior do sistema ACAFE de Santa Catarina. Revista Eletrônica de Ciência Administrativa - RECADM, v. 11, n. 1, p. 48-60, jan./jun. Campo Largo. 2012. Disponível em: <http://www.periodicosibepes.org.br/index.php/recadm/article/view/902/587>. Acesso em: 16 abr. 2018.

NASSAR, V.; VIEIRA. M. L. H. Análise da participação dos usuários nos conteúdos de sites institucionais a partir dos níveis de interatividade. Revista Intercom - RBCC, v. 40, n. 1, p. 121-142, jan./abr. 2017. Disponível em: <http://www.scielo.br/pdf/interc/v40n1/18095844-interc-40-1-0121.pdf>. Acesso em: 26 set. 2017.

OLIVEIRA,V. N. P. A influência dos níveis de interatividade no website institucional. 2012. 172 f. Dissertação (Mestrado em Design) - Universidade Federal do Paraná, Curitiba, 2012. Disponível em: <http://acervodigital.ufpr.br/bitstream/handle/1884/27541/R\%20-

$\% 20 \mathrm{D} \% 20 \% 20$ OLIVEIRA\%2C\%20VICTOR\%20NASSAR\%20PALMEIRA.pdf?sequenc $\mathrm{e}=1 \&$ is Allowed=y>. Acesso em: 04 set. 2017.

OLIVEIRA, Y. R. O instagram como uma nova ferramenta para estratégias publicitárias. Revista Intercom - RBCC, João Pessoa. 2014. Disponível em: <http://portalintercom.org.br/anais/nordeste2014/resumos/R42-0112-1.pdf>. Acesso em: 13 out. 2017.

PATRÍCIO, M. R; GONÇALVES, V. Facebook: rede social educativa? Universidade de Lisboa, Instituto de Educação. p. 593-598, 2010. Disponível em: <https://bibliotecadigital.ipb.pt/bitstream/10198/3584/1/118.pdf>. Acesso em: 12 out. 2017. 
ROCHA JÚNIOR, V. et al. Uso de mídias sociais no setor de ensino superior. Revista Brasileira de Gestão e Inovação, v. 1, n. 2, p. 13-38, jan./abr. 2014. Disponível em: <http://www.ucs.br/etc/revistas/index.php/RBGI/article/view/2442/1479>. Acesso em: 16 set. 2017.

RUF. $O$ que é o ruf. 2017. Disponível em: <http://ruf.folha.uol.com.br/2017/o-ruf/>. Acesso em: 20 jun. 2018.

RUF. Perfil de universidades e faculdades. 2017. Disponível em: <http://ruf.folha.uol.com.br/2017/ranking-de-universidades/>. Acesso em: 20 jun. 2018.

SANTOS, V. S. Ativismo em redes sociais digitais: análise da rede cerrado e suas interfaces na promoção de políticas públicas sustentáveis. $32 \mathrm{f}$. Trabalho de Conclusão de Curso (Bacharel em Gestão Ambiental) - Universidade de Brasília, Planaltina, DF, 2014. Disponível em: <https://periodicos.ufsm.br/REDESG/article/view/15975/pdf\#.WtU3j4jwbIU>. Acesso em: 16 out. 2017.

SILVA, A. L.; VIEIRA, E. S.; SCHNEIDER, H. N. O uso das redes sociais como método alternativo de ensino para jovens: análise de três projetos envolvendo comunidades virtuais. In: COLÓQUIO INTERNACIONAL EDUCAÇÃO E CONTEMPORANEIDADE, 2010. Anais... Laranjeiras. 2010. Disponível em: <http://educonse.com.br/2010/eixo_09/e9-la.pdf>. Acesso em: 18 nov. 2017.

SILVA, I. L. Marketing educacional: novas tendências. 2009. Trabalho de Conclusão de Curso (MBA em Gestão Empresarial) - Centro Universitário Católico Salesiano Auxilium, Lins, 2009.2 Disponível em: <http://www.unisalesiano.edu.br/biblioteca/monografias/49393.pdf>. Acesso em: 20 mai. 2018.

SILVA, P. I. R. Dinâmicas comunicacionais na representação da vida cotidiana Instagram: um modo de narrar sobre si, fotografar ou de olhar para se ver. Revista Intercom - RBCC, Ouro Preto. 2012. Disponível em: <http://www.intercom.org.br/papers/regionais/sudeste2012/resumos/R33-1626-2.pdf>. Acesso em: 13 out. 2017.

SOUZA, D. O uso das redes sociais: uma nova forma de marketing. Revista Borges, Florianópolis, $\quad$ v. 2 2, n. $\quad 1$. 2012. Disponível em: <https://www.revistaborges.com.br/index.php/borges/article/view/22>. Acesso em: 15 out. 2017.

SOUZA, L. M. M.; AZEVEDO, L. E. O uso de mídias sociais nas empresas: adequação para cultura, identidade e públicos. Intercom - RBCC, Rio Branco. 2010. Disponível em: <http://www.intercom.org.br/papers/regionais/norte2010/resumos/R22-0015-1.pdf>. Acesso em: 12 out. 2017.

TOMAÉL, M. I.; ALCARÁ, A. R.; CHIARA, I. G D. Das redes sociais à inovação. Ciência da Informação, Brasília, v. 34, n. 2, p. 93-104, mai./ago. 2005. Disponível em: <http://www.scielo.br/pdf/ci/v34n2/28559.pdf>. Acesso em: 10 out. 2017. 